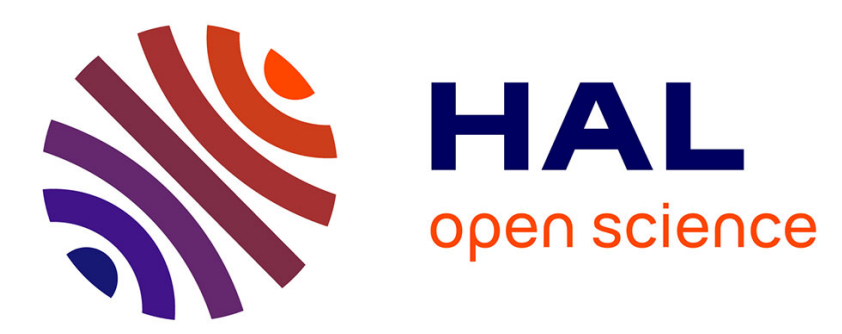

\title{
Using Laboratory Experiments to Design Efficient Market Institutions: The case of wholesale electricity markets
}

Carine Staropoli, Celine Jullien

\section{- To cite this version:}

Carine Staropoli, Celine Jullien. Using Laboratory Experiments to Design Efficient Market Institutions: The case of wholesale electricity markets. Annals of Public and Cooperative Economics, 2006, 77 (4), pp.555-577. 10.1111/j.1467-8292.2006.00319.x . hal-00569121

\section{HAL Id: hal-00569121 \\ http://hal.grenoble-em.com/hal-00569121}

Submitted on 25 Feb 2011

HAL is a multi-disciplinary open access archive for the deposit and dissemination of scientific research documents, whether they are published or not. The documents may come from teaching and research institutions in France or abroad, or from public or private research centers.
L'archive ouverte pluridisciplinaire HAL, est destinée au dépôt et à la diffusion de documents scientifiques de niveau recherche, publiés ou non, émanant des établissements d'enseignement et de recherche français ou étrangers, des laboratoires publics ou privés. 


\title{
Using Laboratory Experiments to Design Efficient Market Institutions The case of wholesale electricity markets
}

\author{
Carine STAROPOLI *, Céline JULLIEN **
}

\begin{abstract}
This paper assesses the contribution of laboratory experiments to the economics of design applied to the electricity industry. The analysis is dedicated to wholesale markets, and reviews the results accumulated to date concerning both the general architecture of power markets and the very details of the market rules or institution, that is the auction rule. We argue that these experimental results contribute to a better understanding of the performances properties and implementation features of competitive market designs and that experimental economics has proven very useful to public authorities to inform the restructuring of electricity industry. It thus confirms the role of experimental economics as a complement to theoretical approaches in the design effort.

Notre article vise à présenter la contribution de l'économie expérimentale à l'économie $\mathrm{du}$ design. Nous nous intéressons plus particulièrement au processus de création d'un marché de gros organisé dans le cadre des réformes de libéralisation de l'industrie électrique. Nous présentons une revue des principaux résultats qui ont été obtenus en laboratoire concernant à la fois l'architecture générale des marchés et le choix de la règle d'enchère. Nous montrons que la méthode expérimentale permet de mieux appréhender les propriétés d'efficacité des marchés électriques ainsi que les enjeux liés à leur mise en œuvre. A ce titre elle a été mobilisée à plusieurs reprises par les autorités publiques en charge des réformes comme un outil d'aide à la décision, confirmant ainsi le rôle de l'économie expérimentale comme complément des approches analytiques dans le design d'institutions d'échange efficaces.
\end{abstract}

JEL-Classification: C9, L5, L94

Keywords: Experimental economics, market design, design economics, electricity auction.

\footnotetext{
* Centre ATOM, Université Panthéon-Sorbonne, Maison des Sciences Economiques, 106-112 boulevard de l’Hôpital, 75634 Paris Cedex 13 France, carine.staropoli@univ-paris1.fr (corresponding author)

*"GAEL, Université Pierre Mendès France, Grenoble, France.
} 


\section{INTRODUCTION}

Over the last decade, the worldwide experiences of restructuring of network industries (electricity, gas, transportation, water) have questioned economists regarding both the theory used to support those liberalization processes and the empirical methods applied to gather relevant regularities. In fact, electricity markets, as other markets to be restructured, do not emerge spontaneously. They are rather "designed" by public authorities in charge of the liberalization process. Hurwizc (1973) first introduced the term "design" to describe a work consisting of "finding a system that would be, in a sense to be specified, superior to the existing one". Since then, emerges in economics what Roth (2002) sees as a new discipline, namely the design economics defined as "the part of economics intended to further the design and maintenance of markets and other economic institutions". In terms of efficiency, there is a tension between the desire for short term efficient competition that should ensure prices reductions, and for long term productive efficiency in terms of investments and security of supply. The introduction of competition between generators requires the implementation of trading arrangements like bilateral contracts and/or organized markets. It raises two types of issues: the market architecture issue and the auction design issue. The architecture issue concerns the replacement of a centralized coordination based on optimization algorithms within a vertically integrated monopoly by a somehow decentralized coordination mechanism between many competing producers with a single transmission system operator (TSO) based on equilibrium logics (a competitive market). The auction design issue refers to detailed design of electricity auctions. Electricity markets are organized as procurement auction, since the product is being procured rather than sold. Generators buy the right to inject electricity in the network, while consumers buy the right to withdraw electricity from the network.

Economists in the design economics field are confronted to the challenging issue of defining what "good" or efficient market designs are, given that dramatic consequences may come from their mis-specification. The so-called California energy crisis in summer 2000 is typically seen as a crisis of bad market design (Smith, Rassenti, Wilson, 2002). Finding its theoretical foundations in the theories of market microstructures, the discipline relies largely on the use of modern empirical methodologies such as computational economics and experimental economics. These later, rather complementary than opposed, are giving economists the possibility to explore and define the efficiency properties of various market designs that are sometimes typically too complex to model using the tools of the 
microeconomic theories (notably auction literature which is according to Klemperer (2002) « of second order importance for practical auction design »). While focusing on the design of labor clearinghouses and the FCC auction for the radio spectrum in his paper, Roth (2002) claims that the electric power industry figures as an interesting applied field in the design economics, illustrating the relevant use that can be made of the experimental economic methodology. As a matter of fact, economists and "experimentalists" have played an active role in the design effort increasing the role of economics as an «engineering » discipline capable of providing guidance on details of market design (Wilson, 2002).

The experimental literature on electricity markets is recent (it coincides with the pioneer restructuring experience in the mid-1980s) and provides relatively few contributions compared to the other experimental domains (like game theory and individual decision making) or for instance compared to the auction theory literature in the economics of design. Both the novelty of the approach and the entry barriers to the understanding and the complexity of the features of the electricity system explain this situation. However, the contributions of laboratory experiments to the design phase as well as to the academic work are increasing and gaining interests. This paper surveys the main contributions of experimental economics to the design of wholesale electricity markets. The purpose of this paper is to present these contributions concerning the design of electricity markets that beyond economists, interest both public authorities as "market designers" and industry participants as "market players". The experimental methodology serves, as in other scientific discipline, as a tool to test assumptions, on economic behaviors and/or on economic system efficiencies, in a controlled and reproducible environment. These fundamental properties creates the possibility both to test the effects of different variables "all things being equal" and to generate enough data to generalized the results.

There are many prominent reasons in the literature as to why economists conduct experiments (Smith, 1992; Davis, Holt 1993). We argue that applied to the design of electricity markets, laboratory experiments fulfils at least two objectives: it helps "searching for facts and meaning" and "speaking to theorists".

"Searching for facts" means looking for regularities and exploring and documenting unanticipated regularities. More generally the experimental methodology provides the tools to do so given that it "uses the lab as a test bed to examine the performance of proposed new institutions, and modifies their rules and implementation features in the light of the test results" [Smith (2002a)]. This step is very useful since it is by definition difficult to gather field data prior to the reform. These empirical regularities may thus serve in the design effort 
(as a testing ground for institutional design or evaluation of policy proposals) but also as a basis for new theory. With laboratory experiments, it is possible to analyze complex situation in the analytical sense. While models can't analytically model more than a simple two nodes network, it is possible (especially with the use of smart computer assisted markets) to run an experiment with a simple 3 - nodes radial network but also with multi nodes networks (up to 30 nodes in Zimmerman, Bernard, Thomas, Schulze (1999)) and the consequential constraints (losses $^{1}$, loop flows ${ }^{2}$, congestion ${ }^{3} \ldots$ ). It is also possible to consider bidding behaviors on sequential auction submarkets (energy, transmission, reserves, and real time for example) thereby dealing with real coordination issues at stake in decentralized designs. It is thus possible to assess the efficiency of auctions when there are multiple units, repeated games, as well as complementarities (over time and between power generation and various ancillary services like reserve capacity needed to keep the transmission network operating). From that perspective, experiments are designed to reproduce the "reality" in the laboratory in order to collect empirical regularities on the industry studied. Even if the experimental design is simplified as much as possible, this type of experiments remains relatively complex, as they keep a high degree of parallelism with reality, incorporating a large number of variables that describe the industry and the good.

As regards "speaking to theorists" type of experiments, Milgrom (2004) emphasizes the extreme complexity to model feasible rules to exchange electricity and the need for complementary approaches "[...] The existing theories oversimplify the way human play games [...] real world auction design must be undertaken like other practical arts, by mixing theory with experiments and practical judgment". The experimental methodology gives economists the possibility both to treat the specific aspects of market designs and to go beyond the boundaries of market microstructure theories. For that purpose, experiments are designed to study and assess the performance of existing or new market rules or institutions in a more "simple" environment as compared to reality (in terms of the number of variables incorporated in their design and interactions among these variables). However, they always incorporate some features of an electricity system which makes them more or less dedicated.

1 A small percentage of the energy produced by the generators is dissipated by the transmission lines. Among other things, the amount of power lost depends on the flow in the line and the length of the line.

2 With such complicated but realistic network, the problem is that there are multiple paths for power to flow between any two points which introduces interdependencies. On the contrary in a radial network, nodes are in line such that power from any source flows on a single path to any sink

3 There are limits on the amount of power that can be transmitted from any given location to any other location. Limits concern the line capacity or the voltage or stability. Congestion occurs when one or more of these network limits is reached. 
The experiments focus for example on one component of auction rules (typically the pricing rule - uniform vs. discriminatory - or the bidding process - sealed bid vs. continuous oral auction) and their effects on market efficiency. They may also assess the robustness of one simple institution to the introduction of market power.

Overall, laboratory experiments help to gain insights on the efficiency of electricity markets under a controlled environment. As such, they should be taken as a complement to analytical approaches and as a tool to "whisper in the ears of princes" both in the design and the "re-design" phases, when it is time to correct a bad market design". This type of experiments aimed at finding empirical regularities to evaluate some policy proposals with no real visibility at the time it was decided to reform the industry (early 80s) or to compensate the lack or the limitation of analytical results due to the complexity of trading arrangements.

The paper is organized in two sections. Section two deals with what Wilson [1999] identifies as "the general architecture of the market" in a design economics perspective. At this level, experiments have notably helped to assess the feasibility of decentralization and the impact of demand side bidding on the market. Section three presents the main results regarding the details of market institution (as opposed to the general architecture), i.e. the auction rule. We illustrate and confirm that experimental economics has contributed to assess the relative merits of alternative auctions specifications (bilateral versus unilateral, sealed-bid versus continuous auctions, uniform price versus discriminatory prices auctions) with regard to market efficiency, contributing to the discussions on methodological issues in the analysis of electricity auctions. Section four concludes.

\section{THE USE OF LABORATORY EXPERIMENTS TO "SEARCH FOR FACTS AND MEANING"}

Pioneer experiments applied to electricity market designs were run to study the feasibility of restructuring, as it has been done before in other network industries. The agenda was thus to deal with design issues concerning architecture of the market such as the extent of

\footnotetext{
4 Indeed, in the last ten years most of the countries that chose to restructure their power industry (like England and Wales, Australia, or the United-States) are now experiencing new phases to re-design their industry in order to correct the observed inefficiencies. This tendency is explained by the fact that the design of markets happens to be a "trial and error task", with both field experiences and theory lacking from definitive answers. There is still no best way to proceed to the corrections. Some have chosen to correct marginally the existing design (in that case, they may use laboratory experiments to compare institutions using identical environment) or to impose further restructuring so as to reduce market powers (in that case, laboratory experiment help to compare environments using the same market institution). Others have chosen to change radically the design (as in England and Wales with the replacement of the Pool by the NETA) while letting market forces influencing industry structures. In that case, laboratory experiments are used as the same manner as in the design phase.
} 
decentralisation of trading, the management of network constraints given the level of integration of sequential markets (energy, transmission capacity, reserve) ${ }^{5}$, and the participation of demand. We examine what has been learned in the laboratory on these three aspects which are fundamental "Architecture" issues.

\subsection{The extent of decentralization}

The creation of a market place induces the replacement of a centralized coordination mechanism based on optimization algorithms within a vertically integrated monopoly by a somehow decentralized coordination mechanism between competing producers and usually one single transmission system operator (TSO) who is in charge of the operation on the network ${ }^{6}$. Such coordination is based on competitive equilibrium logics. The challenge for the development of new trading arrangements such as procurement auction is to keep the cost of vertical disintegration as low as possible with undermining too much the benefits of competition.

A first step in the analysis has been to address the feasibility an efficiency of such a process of decentralization of the dispatch associated with vertical and horizontal separation of the incumbent monopoly. Joskow and Schmalensee (1983) were among the first to discuss the practical introduction of competition wherever possible in the electricity industry. Even if nowadays no one would contest its accuracy, at the time the question was first addressed (in the mid-1980s), there was still a large part of economists defending the "natural monopoly" argument, and the existence of network externalities to justify a centralized organization of the electricity industry (and an integration of production and transmission). Moreover, the industry had for long time been dominated by engineers who were reluctant to switch from an "engineer culture" to a "market" one. It was therefore a serious and challenging question to ask whether the industry, that proved to work efficiently (at least in terms of productive efficiency, investment incentives and reliability of the system) with a central planning of both technical and economic dispatches, should be restructured and how to proceed.

In 1984, the Arizona Corporation Commission solicited the experimental economics group headed by Vernon Smith at the University of Arizona to study the deregulation of the

\footnotetext{
${ }_{6}^{5}$ For a general presentation of electricity market design issues, see Wilson $(1999,2002)$.

${ }^{6}$ Restructuring the electricity industry consists in introducing competition wherever possible (basically in generation and supply). It induces vertical (and often horizontal) separation of the incumbent vertically integrated monopoly. The introduction of competition in generation means that the producers compete to obtain the right to inject energy in the network. The competitive process thus aims at determining the dispatch of generating stations, i.e. for a given period of time, which units will produce, how much and when.
} 
electricity industry. Their research was the first step into the application of the experimental economics methodology to the economics of systems designs in the electric power industry. It was made possible by the use of smart computer assisted markets that over-passed the technical optimization issues. The key questions as reported by the authors (Rassenti, Smith, 1986) were (i) first to know if the decentralization was even feasible, in other words, to question whether a decentralized economic coordination combined with a centralized technical one could be efficient and (ii) second to evaluate how the demand-side bidding was affecting market performance. Their study led to many detailed recommendations concerning basic architecture issues such as the separation of generation and wires, the characteristics of the spot market mechanism and the allocation of property rights in the network. Overall they concluded that experimental markets figuring energy sales and purchases expressed as "offers to sell" and "bids to buy" so that allocation were determined simultaneously given physical properties of the grid, was not only feasible but also efficient.

Although the authors experienced a strong reticence by the Arizona Corporation Commission against their final recommendations of a highly decentralized, vertically unbundled and privatized electricity system $^{7}$, this first study initiated a large agenda of research both for theorists and experimentalists. Notably, they emphasized the fundamental and unintuitive role of demand side bidding to ensure real competition. Indeed, the industry had historically a strong supply side orientation at that time (little was done to encourage consumer to be more reactive to electricity prices) and the demand was considered as entirely inelastic. They also showed that efficiency losses due to short-run network externalities (losses and congestion) were negligible as soon as they could be internalized via a simultaneous submission of bid/ask schedules linked with system constrained (i.e. a sealed bid auction in a centralized market). Unsurprisingly the experimentalists' credo "institutions do matter" applies for electricity market as well as (if not more than) industry structure. The design effort is thus crucial for the success of the electricity industry restructuring.

\subsection{The impact of network constraints}

Network constraints arising from line, voltage or stability limits raise generic problems: basically, scarce transmission capacity has to be efficiently allocated to avoid electricity generation facilities to exploit market power that transmission congestion creates. One advantage of experimental economics is to be able to deal with complexity under controlled

\footnotetext{
${ }^{7}$ As suggested by the authors, the reticences were mostly due to political factors.
} 
environment by using smart markets while analytical results are limited to two nodes network. In multi nodes networks, countervailing effects make an analytic analysis difficult. Complications with the operation of an electric grid including the stochastic nature of load, the associated need to maintain reliability voltage and line limits, and the locational variability of transmission losses, the existence of constraints in the network can be incorporated in the experimental environment. It then allows dealing with the most important issues related to transmission constraints such as monopoly power of the owner of wires (the transmission system operator, TSO), local market power of some generators, as well as the allocation of ownership rights to use the network. Below, we develop on these main issues.

\subsubsection{Monopoly power of the TSO}

The Transmission System Operator (TSO) is in charge of maintaining the integrity of the network. As such, he has the monopoly over the activity of "managing the network", i.e. producing the so called "technical dispatch" that determines who produce, when and how much. In case he owns transmission lines and/or generation capacity he may abuse his monopoly power to capture the congestion rents extracted from transmission capacity scarcity. A typical behavior could be to distort information on scarcity to manipulate producers' anticipations. He may also simply create congestion physically through the management of the network. Other inefficiencies may occur from bad incentives. When transmission and generation were vertically integrated, investment decisions in transmission and generation assets were made jointly. Vertical disintegration strongly modifies investment incentives since the TSO may take advantage from congested rents as well as generators with local market power.

Backerman, Rassenti, Smith (2000) sat-up an experimental design in order to determine under line constraints who, among the generators of electricity, the distributors (demand side) and the transmission line owners, receive the congestion rents and how the distribution of the profits between participants varies under alternative auction rules. The experimental environment represents a three nodes radial network, with four distributors at one central node and three and four generators respectively at the upstream and downstream nodes. The two transmission lines are subject to losses and constraints, they are owned by a passive (non strategic) agent, the pricing of incremental losses being determined following the standard optimization theory (Schweppe, Caramanis, Tabors, Bohn 1988). Both sides of the market are participating to the pricing of electricity that is ruled by a uniform price double auction mechanism (UPDA). Two alternative rules of the UPDA are analyzed (see for details on the 
UPDA McCabe, Rassenti, Smith (1991)): the "both-sides rule" that gives the opportunity to any participant in the market place to accept any offers on each side of the market before the market is called; and the "other-side rule", in which in order to have an offer accepted, each participant must meet the terms of the unaccepted bid or ask on the other side of the market. In theory, the transmission owner of the upstream congested line should at the same time receive the congestion rents and pay the transmission losses when his line is constrained. Given the experimental design that allows both producers and distributors to make offers for electricity at each node, the authors expected the following two results: First, that when the upstream line is constraint, upstream generators will increase their offers, inducing an increase of the market price at that node, and therefore capturing part of the rent accruing to the line owners; And second that the market efficiency should be greater under the both-side rule, given the incentive characteristics of this market institution. The experimental data support these two propositions, showing also that the revenues of distributors are not affected by congestions. Overall, this experiment suggests that in this environment, no incentives are given to transmission line owners to invest in new transmission capacities as they do not capture the rents in the system, whereas regarding dynamic efficiency they should. In other words, in terms of policy implications, the decentralized design of power market must integrate elements that counter the abilities of generators to capture the rents in the system and game it when pricing at each nodes. These elements may be found in a structural reorganization of power plants and portfolios in the system, or in the market institution used to organize the exchange.

\subsubsection{Local market power}

Particularly for electricity, market power cannot be assessed based on traditional concentration measures alone. Notably, there is another type of market power, the local market power, which depends essentially on the localization on the network and the temporary topography of the network. When a transmission line is constrained, the TSO may order generating facilitates at specific locations on the network (upstream side of the congestion) to inject power in order to solve the problem. In that case, no matter the price the generator charges, the TSO will accept his conditions. Simultaneously he will order other generating facilities at other specific locations, not to inject what they ought to. When inexpensive generation is unusable due to its location, making it necessary to utilize a more expensive unit in different location, it creates unavoidable inefficiencies. If generators know that they will be called by the TSO to produce (as incumbent they have a good knowledge of 
the network), no matter the price they charge, they are in a position to charge very high prices. Those generators have "local market power" (because it depends on transitory system conditions and on their localization on the network). Some generators may thus charge extremely high price but they can also withdraw or inject capacity on one side of the node to voluntary create or solve congestions to their own advantage. This local market power strongly depends on the congestion management scheme, i.e. the mechanism used by the system operator to solve the congestion. The choice of a proper congestion management scheme (auction, contracts, administered rules such as first arrived first served, grandfathering) is thus crucial for market efficiency.

Zimmerman, Bernard, Thomas, Schulze (1999), designed a web-based experimental platform (so-called "PowerWeb") based on smart computer assisted markets, to study also how transmission losses and congestions affect market prices and performance in a thirtynodes network under different market size (two, four and six competitors) using a uniform price sealed-bid auction. The six generators own the same portfolio, two of them being located in the upstream congestion part of the network. The demand side is absent in the experiments. The results show that market prices are close to the duopoly levels in the congested area of the network, where the two generators can exercise market power, and more volatile from period to period than in baseline treatments where no market power can be exercised. Finally, the authors captured in the laboratory typical supra-competitive pricing behaviors that occur when transmission lines are constraints. They conclude on the role of the market structure, i.e. the number and the size of generators at each node, to solve the problem, although opposite arguments may be given in the direction of a change in the sole institution. Here again the results suggest a particular treatment of individual incentives given to generators to make offers reflecting their costs through the market mechanism.

\subsubsection{The allocation of ownership rights to use the network}

Motivated by the question of how to solve the problem of market power that comes from line congestion, Kench (2004) focuses on the impact of property rights, either financial or physical, on market efficiency. Kench defines financial rights as entitlement to collect a share of the congestion rent generated on a specific transmission line, whereas physical rights authorizes their owners to send units of power through a specific transmission line in a given direction. He argues that besides investing in transmission capacity (which is a long term solution), allocating transmission rights with the use of electricity transmission network and creating markets to allocate those rights could potentially resolve local market power. This 
contradicts the analytical results of the radial electricity model presented in Joskow, Tirole (2000). Joskow and Tirole (2000) found that the absence of transmission right is as efficient if not more efficient than any of the two rights systems.

Kench investigates the effects of the two different property rights regimes in the context of a two-nodes network, with four buyers and four high-cost sellers on the downstream node (the south), and four low-cost sellers on the upstream node (the north). Only northern generators can inject electricity in the network, the line being constrained by a certain capacity (no transmission losses are incurred). There exists more northern generation capacity than transmission capacity and southern generation is thus required to meet market demand. In the experimental treatment the congestion rents based on the differences in prices between the two nodes are captured by the benevolent system operator (i.e. the experimentalist). The transmission rights are randomly allocated to the northern generators, and then auctioned for reallocation from period to period. They are allocated to those who value them the most. The market institution used to trade electricity at each node is the continuous double auction, where both the demand-side and the seller-side are active. The congestion on the line should generate high prices at the upstream node. The attribution of both financial and physical property rights should reduce or eliminate this tendency. Overall, the results show that the physical rights are marginally more efficient than financial ones, and that both treatments exhibit high efficiency rates. However, there is a difference between the south and the north. Market prices tend to converge to the competitive equilibrium in the south but are much higher in the north. Moreover there is a significant difference between financial right and physical rights regime in the north as when a northern generator does not have a physical right the market price is lower than when a northern generator does not have a financial right. The author conclude on the facts that no striking differences allow to discriminate among the two property rights regimes in the south, although both of them increase the efficiency of the market compared to a baseline experiment without property rights. But in the North, results depend on the property right regime. Put it differently and once again: institutions do matter! Kench (2004) argues that the physical rights regime helps to remove uncertainty about transmission congestion (and the related generator profits) in a way that financial rights regime and even more no property right regime cannot. Because northern generators without financial rights are uncertain about their net profit (which depends on the charge) they have an incentive to raise their reservation price higher than marginal cost to compensate for the potential charge. In doing so, they increase market prices. At that point of simplification, physical rights regime is promising. Still, the author makes special caveats regarding the 
policy implications of his results. He considers them as a first step feeding the debates especially with theorists and suggests to conduct further experiment to understand the efficiency properties of physical rights in a more complex network taking into account loop flows.

\subsection{The impact of participation of demand}

It is worth noting that the literature contains remarkably little discussion of the impact of demand response in the electricity market although practically, it was progressively recognized that demand response may solve some market power problems and have some benefits on price volatility (Ruff, 2002). Initially, short run demand response was not considered as a relevant issue probably because electricity demand was considered quasiinelastic in the short term. It was as if demand side was absent of the market. Things have evolved and it is now recognized that the introduction of demand side bidding in the spot market should reduce the total cost of meeting demand reliably and reduce the level and the volatility of spot price during peak periods. Since the seminal contribution of Rassenti and Smith (1986), the impact of demand side bidding has been tested in the laboratory with significant results that confirm the fact that demand side biding can discipline generators. In Rassenti, Smith, Wilson (2002), the authors ask whether in the laboratory the active participation of the demand side to the trading of electricity does improve or not the performance of markets in situations with and without market power. They conducted two sets of experiments: one using robotically revealed expression of demand and one using profit-motivated human subjects who have the option to interrupt voluntary their purchase (because their demand is not sensitive to continuity of supply ${ }^{8}$ ). Their significant result is that demand-side bidding (using discretionary demand steps reflecting the prices above which they are prepared to reduce demand by invoking their contracts for interrupting deliveries ${ }^{9}$ ) neutralizes market power and price spikes on peak in the laboratory as well as it lowers prices. These results have been confirmed in Rassenti, Smith, Wilson (2003). Analyzing further the conjunction effects of demand-side bidding and market concentration (three versus six generators) in Denton, Rassenti, (2001), the authors report no differences in market prices and performances related to the market structure, the participation of the demand providing the condition for higher market efficiency in both situations. Concluding on the policy

\footnotetext{
${ }^{8}$ This hypothesis is credible since in reality there are between 15 and $20 \%$ of peak demand that can be interrupted temporarily, shutting of interruptible loads.

${ }^{9}$ This introduces uncertainty on demand level and consequently, demand side bidding can better deter supply side market power.
} 
implication of these results, the authors argue that "Demand-side bidding, coupled with the supporting interruptible-service incentive contracts, can eliminate price spikes and price increases, and reduce the need for reserve supplies of generator capacity and transmission capacity". In terms of policy conclusions, they claim that empowering the wholesale buyers is a credible alternative to the control of both the supply-side market power and the price volatility which are the two main threats for market efficiency.

\section{THE USE OF LABORATORY EXPERIMENTS TO DESIGN ELECTRICITY AUCTION}

Electricity wholesale markets are organized as auction markets. Understanding the auction rule, which is at the heart of the market, is thus central to anticipate how participants will behave, given the rules on who will win and at what price the product will be sold. Electricity wholesale markets are structured as "procurement auction", since the product is being procured rather than sold. The way electricity auctions proceeds (i.e. the way bids are transmitted) is rather specific compared to other auction processes. The other components of the auction rule - the payment rule as well as the allocation rule - are not specific to the electricity auction. Indeed, as for other auctions, there is a trade off between the uniform price auction and the discriminatory auction, the sealed-bid auction and the double oral auction or the first price and the second price auction. Still, these tradeoffs remain theoretically controversial.

Much of the recent debates concerning the efficiency of electricity markets have focused on the merits and demerits of different auction formats. Many contributions in auction theory have dealt with the change from uniform pricing to discriminatory pricing, but mostly in the case of a single-unit auction in different contexts (in terms of information) ${ }^{10}$. Unfortunately, these results cannot be generalized for electricity auctions, which usually involve an oligopoly of asymmetric bidders who meet repeatedly and frequently to bid for the same commodity. However, some recent contributions explicitly motivated by the British experience have tried to evaluate the impact on prices of a change from a uniform price

\footnotetext{
${ }^{10}$ Milgrom [1989] showed that the uniform price auction has a lower winner's curse and produces greater revenue for the seller of a single and indivisible good than does discriminatory auction. In the matter of the Treasury bond case, Back and Zender [1993] find collusion harder with discriminatory auction compared to the alternative uniform price auction. They also show that this result is critically dependent on the assumption that the good is indivisible. With a repeated auction, Goswami et al. [1996] find that when participants are allowed to communicate before bidding, the resulting collusion has a worse impact on efficiency with a uniform price auction than with a discriminatory auction. Chari and Weber [1992] argue that uniform price auctions reduce incentives for market manipulation. Dealing with Mexican data on the Treasury auction, Umlauf [1993] finds that uniform price auction helps reduce bidders' profits in comparison to discriminatory auction. Tenorio [1993] reaches the same conclusion with data from Zambia's foreign exchange auction.
} 
auction to a discriminatory one [Fabra, 2000, Federico and Rahman 2000]. These papers focus on the impact of the alternative auctions on market prices. The general conclusion of these papers is that the discriminatory auction may help reduce market power, contrary to a uniform auction which contributes to increase price when the demand is uncertain, but there is no evidence that it produces fully efficient outcomes. Overall, these conclusions invite criticisms of the Britain's choice to switch from uniform pricing in the Pool to discriminatory pricing in the NETA for it was not theoretically founded.

What makes electricity auction rather different from other auctions is the fact that they are multiple units auctions and they occur in repeated games. In practice, in a centralized market generators offer every half hours or one hour willingness to produce (in MW) and a price against which they would like to do so through a discrete step function. On the basis of these price-quantity offers, a least-cost plan of generating units is drawn up. If all generating units had the same cost structure, the auction would be like a single unit auction, since each producer having many generating unit would not need to submit a bid for each unit. But since each producer has many units with different operational characteristics, he needs to submit different bids for each of his units. The market operator thus has to accept bids from different generating units so as to fulfill demand. Analytically, it is not possible to extent the single unit auctions properties to a multiple unit auction [Klemperer, 2004]. The state of discussion is thus rather limited for this type of auction. Furthermore, the dynamic optimization process induces time complementarities in auction. Practically a producer who has an inflexible generating unit is willing to produce continuously rather than having to shut down. This requires package bidding (in time) for which once again properties are not well known.

Models are limited in their ability to capture of important characteristics of the electricity auction rule. Indeed, most of them assume that bidders make competitive bids, once only, for a unique good and that they are risk neutral. Nevertheless, in reality, games are frequently repeated, bids may run over multiple periods, and multiple units are sold simultaneously. Still ill-equipped to deal with such features, it may therefore be concluded that the literature presents a rather inconclusive if not confusing picture and that it calls for complementary approaches to help reducing the confusion [Sweeting, 2000].

The experimental analyses of the details of market mechanisms in electric power industry respond to two specific questions. The first one concerns the timing of auction in the spot market, and is to know whether sealed-bid (i.e. simultaneous) auctions perform better than continuous double auctions (i.e. sequential) or not. The second question is related to the price outcome in auctions and is to differentiate between uniform price and discriminatory 
prices auctions. Overall, most electricity market experiments deal with such comparisons of alternative institutional arrangements. It may be explained by the fact that there is analytically no consensus on the respective impact of different auction rules due to its complexity. An other reason is that it allows to run relatively simple market design (no network constraints) and focus on the robustness of the institution towards market power or the introduction of demand side bidding (bilateral auction vs. unilateral auction for example). Below, we sum up the main conclusions of the experiments focusing on comparative analysis of alternative auctions on these two issues.

\subsection{Timing of auctions: Sealed-bid versus continues double auctions}

A first experimental analysis by Bernard, Mount, Schulze (1998) compares two uniform price auction rules under three different market structures. The authors questioned whether the last accepted offer (LAO) auction, known also as the standard sealed-bid auction (or the "merit order") performs better or not than the first rejected offer (FRO) auction. These mechanisms differ only regarding the offer that serves to set the market price. The issues addressed by the authors were of primarily interest at the time of their research, as much of the northeastern States were figuring restructuring proposals for their energy markets. They concern typically the properties of the two auctions to induce costs revelation, and the extent to which participants can gain excess profits through gaming in these auctions. The market structure varies in the experiments according to the number of generators that are either two, four or six competitors by treatments. The demand-side of the market is absent, the inelastic forecasted level of demand serving to determine the equilibrium quantity in the market for each period. The theoretical property of the two auctions in case of the single unit show that the FRO is incentive compatible whereas the LAO is not. But in the case of multiple units as in the experiments, the properties of the FRO do not carry over. Finally, the authors report results showing that the last accepted offer auction performs slightly better that first rejected offer, and that market concentration leads to a significant and large increase in market prices under this institution. Overall, Bernard, Mount, Schulze (1998) results give support the more commonly use auction, namely the merit order (or LAO), showing at the same time its gaming properties whenever the market structure is concentrated. These results are particularly interesting in light of the England and Wales market, where such inefficiencies were observed during the time of the Pool implementation before its replacement by the NETA (New Electricity Trading Arrangement). 
Denton, Rassenti, Smith (2001) propose a comparison of the sealed-bid offer (SBO) with the real-time uniform price double auction market (UPDA). Generators are endowed with identical portfolios, and owned generation plants that are characterized by both incremental and start-up costs. The authors report striking results showing that the SBO is significantly more efficient than the UPDA institution. Moreover this later institution (UPDA) appears to perform poorly given the cost-structure environment, compared to traditional convex environment where it is known to usually perform very well.

\subsection{Pricing outcome: Uniform price versus discriminatory prices auctions}

At the time of the pioneer's reforms of power markets, Han and Van Boening (1990) proposed an interesting comparison of the SBO with the split-saving rule (SSR) discriminatory auction which was already used in the loose pools in the US (Joskow, Schmalensee, 1983). In this later institution, the highest bids and the lowest offers are systematically matched in order until bids are less than offers, and each market price is determined as half of the sum of the matched bid and offer. They show that price deviations from the competitive equilibrium were more likely under SSR than under SBO, in other words that the uniform price auction performed better than discriminatory one, whereas both institutions yield on average $90 \%$ of efficiency. However, they conclude by highlighting the inconclusive effects of both institutions on surplus splitting in the experiments.

Comparing the day-ahead sealed bid-auction (SB) and the simultaneous continuous double auction (CDA) Olson, Rassenti, Smith, Rigdon (1999) found similar results as Han and van Boening (1990), in a more complex environment. Figuring in the laboratory a complex nine nodes network with eight generators possessing min load capacities, marginal costs plus start-up costs and start-up times, a succession of a day-ahead energy market, followed by a reserve market and adjustment market, they investigated the performance of each institution. They report that market efficiencies are high in both markets, but that SB markets are on average $2.5 \%$ more efficient that CDA ones. Moreover, CDA market exhibit costs that are on average $10 \%$ in excess of the costs incurred in SB markets. Finally, CDA prices are maintained at higher level than SB prices, and sellers capture more of the surplus of the buyers with this institution. The results suggest that discriminatory auction create the condition for higher and more volatile market prices and that the consumers in the markets distributors - are poorly efficient in this institutional arrangement. Assessing earlier in Rassenti, Smith, Wilson (2001a) that demand-side bidding may dramatically change the outcomes of power market, the later results insist on the fact that incentives for generators to 
lower prices and invest in new generation plants come from the demand-side of the market. Therefore, although the repartition of the surplus in the market does not affect static efficiency, one main argument is that the repartition itself creates the condition for the distortion of markets performance in the long run.

Inquiring the question of the effect of market power in the two different market institutions, Rassenti, Smith, Wilson (2001b) show that in discriminatory auction markets, in the absence of market power, market prices converge to higher prices than in experiments with the uniform price auction and market power. Overall, they conclude that the discriminatory institution in a no market power environment is as anti-competitive as a uniform-price institution with structural market power. These results are in line with the two previous ones: Discriminatory auctions perform poorly in electric power markets.

Abbink, Brandts, McDaniel (2003) investigating the effect of the information uncertainty about the demand in both the uniform-price and the discriminatory price auction show that whereas no significant differences in terms of average transaction prices and price volatility are observed in the laboratory between the two institutions when the information is symmetric and common, with asymmetric information among sellers, the discriminatory auction is significantly less efficient than uniform price auction, price spikes being more frequent under discriminatory auction.

\section{Conclusion}

This paper presents the experimental results accumulated to date on the design of electricity markets. We identified the critical issues in the design of wholesale power markets, showing that alternative rules and choices can be made, and suggesting that the efficiency of these market designs can hardly be understood using the traditional analytical approaches alone. Certainly, the auction theory contributes to assess the likely impact of market rules on the effectiveness of competition, but leads to rather inconclusive results when facing complex mechanisms. We argue that the practical design of market calls for complementary approaches, and indeed that experimental economics can provide useful empirical insights into the assessment of efficient wholesale electricity markets. As such it should help to go beyond the testimonial conjectures which are often taken as basis for designing a complex trading arena. 


\section{REFERENCES}

ABBINK, K, BRANDTS J., and MCDANIEL T. (2003) "Asymmetric demand information in uniform and discriminatory call auctions: an experimental analysis motivated by electricity markets", Journal of Regulatory Economics, 23:2, 125-144

BACKERMAN S. R., RASSENTI S.J., and SMITH V.L. (2000) "Efficiency and Income Shares in High Demand Energy Networks: Who Receives the Congestion Rents when a Line is Constrained?”,Pacific Economic Review, Vol. 5, n³, 331-347.

BERNARD, J.C., MOUNT T. and SCHULZE W, (1998) «Alternative Auction Institutions for Electric Power Markets », Agricultural and Ressources Economics Review, pp125-131.

DAVIS D.D., HOLT, C.A. (1993) Experimental Economics, Princeton, NJ: Princeton University Press.

DENTON, M., RASSENTI S.J., and SMITH V.L. (2001), "Spot Market Mechanism Design and Competitivity Issues in Electric Power", Journal of Economic Behavior and Organization, Vol. 44, pp435-453

FABRA, N. (2003) "Tacit Collusion in Repeated Auctions: Uniform vs. Discriminatory”, Journal of Industrial Economics, (1), n²3; 271-293.

FEDERICO, G., RAHMAN, D. (2000) "Bidding in Electricity Pay-as-Bid Auction", Annual European Conference 2000, Bergen, Norway.

HAHN, R.W., and VAN BOENING M.V. (1990), «An Experimental Examination of Spot Markets for Electricity », The Economic Journal; Vol. 100, pp1073-1094.

HURWICZ, L. (1973) “The Design of Mechanisms for Resource Allocation", American Economic Review, Vol. 63, n², 1-30.

JOSKOW, P.L., SCHMALENSEE, R. (1983) Markets for Power, An Analysis of Electrical Utility Deregulation, The MIT Press

JOSKOW, P.L., TIROLE J. (2000) “Transmission Rights and Market Power on Electric Power Network”, Rand Journal of Economics, Vol. 31, n³, 450-487.

KENCH, B.T. (2004) «Let's get Physical! Or Financial? A study of Electricity Transmission Rights », Journal of Regulatory Economics, Vol. 25, n², 187-214.

KLEMPERER, P. (2002), "What Really Maters in Auction Design”, The Journal of Economic Perspectives, Vol. 16, No. 1, 160-189. 
MCCABE, K.A., RASSENTI, S.J., SMITH, V.L (1991) “Designing Smart COmpouter Assisted Markets", in Papers in Experimental Economics, Smith, V.L. Ed., Cambridge University Press: New York

MILGROM, P. (2004), Putting Auction Theory to Work, Series: Churchill Lectures in Economics, Cambridge University Press.

OLSON, M.A., RASSENTI S.J., and SMITH V.L., RIGDON M.L. (2001), "Market Design and Motivated Human Trading Behavior in Electricity Markets", Institute of Industrial Engineering Transactions, forthcoming.

RASSENTI S.J., and SMITH V.L. (1986), "Electric Utility Deregulation", Pricing Electric, Gas and Telecommunication Services, The Institute for the Study of Regulation.

RASSENTI S.J., and SMITH V.L. (1998), "Deregulating electric power: market design issues and experiments", in Designing competitive electricity markets, by Hung-po Chao and Hillard G. Huntington, Kluwer Academic Publishers.

RASSENTI S.J., and SMITH V.L., and WILSON B.J. (2002), "Using Experiment to Inform the Privatization/Deregulation Movement in Electricity", Cato Journal, Vol. 21, No. 3, pp515-544.

RASSENTI S.J., and SMITH V.L., and WILSON B.J. (2003),’Controlling market power and price spikes in electricity networks: Demand-side bidding”, PNAS, Vol. 100, n 5 pp29989-3003.

RASSENTI S.J., and SMITH V.L., and WILSON B.J. (2003), "Discriminatory Price Auctions in Electricity Markets: Low Volatility at the Expense of High Price Levels", Journal of Regulatory Economics, Vol 23, n², pp109-123 .

RASSENTI S.J., and SMITH V.L., and WILSON B.J. (2001a), “Turning Off the Lights", Regulation, pp57-76.

RASSENTI S.J., and SMITH V.L., and WILSON B.J. (2001b), “California: Energy Crisis of Market Design Crisis?”, WP, ICES, Washington.

ROTH, A.E., (2002) “The Economist as Engineer: Game theory, experimentation, and computation as tools for Design Economics", Econometrica, Volume 70, Issue 4, pp13411378.

RUFF, L.E. (2002) "Economic principles of demand response in electricity", Edison Electric Institute

SCHWEPPE, F.C.; CARAMANIS, M.C.; TABORS, R.D.; BOHN R.E. (1984) $\underline{\text { Spot }}$ Pricing of Electricity, Kluwer Academic Publishers. 
SWEETING, A. (2000) "The Wholesale Market for Electricity in England and Wales: Recent Development and Future Reforms”, WP, MIT-CEEPR, 2000-007.

SMITH, V.L (1992) Economics in the Laboratory, Mimeo, George Mason University, Washington: http://www.ices-gmu.net/article.php/369.html

SMITH, V.L (2002a), "Constructivist and Ecological Rationality in Economics", Interdisciplinary Center for Economic Science.

SMITH, V.L. (2002b), "Method in Experiment: Rhetoric and Reality", Experimental Economics, Vol. 5, pp91-110.

SMITH V.L., RASSENTI S.J., and WILSON B.J. (2002), "California: Energy crisis or market design crisis?", IFREE Mimeo, George Mason University, Washington.

THOMAS R.J, MOUNT, ZIMMERMAN R.D, SCHULZE W., SCHULER, CHAPMAN (2002), "Testing the Effect of Price Responsive Demand on Uniform Price and Soft-Cap Electricity Auction", Proceedings of the $35^{\text {th }}$ Hawaii International Conference on System Sciences.

WILSON, R (1999), "Market Architecture”, Working Paper, Stanford University.

WILSON, R (2002), “Architecture of Power Markets”, Econometrica, Vol. 70, pp12991340.

ZIMMERMAN, R.D.,. BERNARD J.C, Thomas R.J., SCHULZE W. (1999) «Energy Auctions and Market Power: An experimental Examination », Proceedings of the $32^{\text {nd }}$ Hawaii International Conference on System Sciences. 